\title{
UAV and site investigation for evaluation of landslide hazard: a case study in Cipularang Km.92 Toll Road
}

\author{
Andy Sugianto ${ }^{1, *}$ \\ ${ }^{1}$ Department of Civil Engineering, Parahyangan Katolik University , Jl. Ciumbuleuit No.94, Bandung, 40141, Indonesia \\ E-mail:andysugianto.sorong@gmail.com
}

\begin{abstract}
Application of Unmanned Aerial Vehicles (UAV) or drones to detect landslide Hazard and risk assessment becomes uncommon methodology in Indonesia. Nowadays, in Indonesia drones are still popular to use for commercial, news interest and advertisement purposes only. It is not mainly used for detecting landslide hazard or risk assessment purposes. Furthermore, the landslide in Indonesia is a common worldwide phenomenon that often occur and can have a great impact on the infrastructures and sometimes tragically result in fatalities. UAV provide a quick, safe, effective, and potentially superior means of inspecting large-scale, remote and difficult to access landforms with significant cost benefits compared to traditional inspection method by manual tracking. UAV can derive the aerial photography which represents actual condition and landslide hazard instantly. By using an aerial photograph, it can simplify the engineer to obtain viewpoint and presumption related with the mechanism of the landslide, some factors triggering the landslide (terrain and topography, drainage, river stream, logged area, slope height, structure, and community, etc). The result suggests that UAC can be one of most effective value in surveying and large-scale inspection to determine landslide hazard as well as general site condition.
\end{abstract}

\section{Introduction}

The term landslide is sometimes felt to be inadequate because many types of slope movement do not involve sliding. The geomorphologist term mass wasting is little improvement. Cruden (1991) has suggested a simple definition of a landslide: the movement of a mass rock, debris, or earth down a slope.

The dimensions and geometry of a landslide have been described by Varnes (1978) using the cutaway drawing shown on Fig. 1. The main objective in the landslide which needs to be determined are length, width, depth, and slope (average gradient of horizontal: vertical) of the landslide. 14

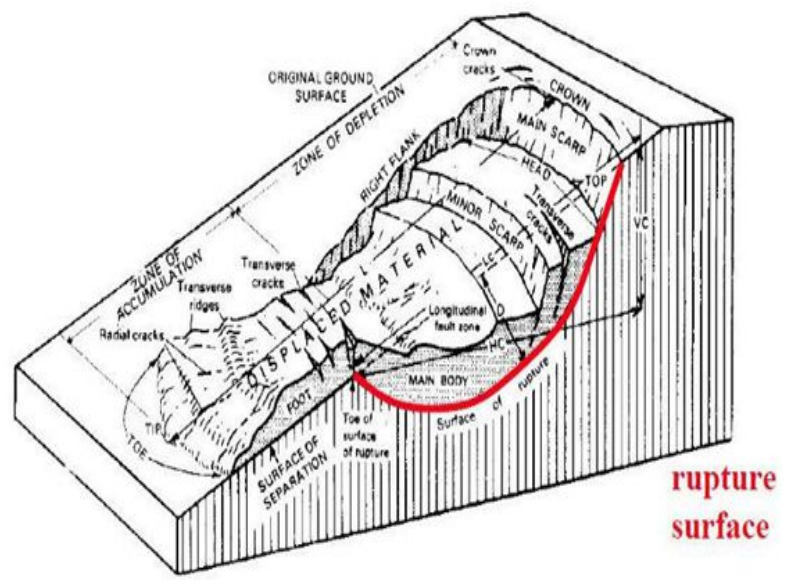

Fig. 1. Terminology for describing landslide features (modified from Varnes, 1978)

In geotechnical engineer point of view, determining the appropriate mechanism of landslide and potential hazard is the main key to decide slope protection and reinforcement in order to prevent future collapse or catastrophic failure. In a small hazard area, it was easy to conduct an inspection, site survey, and any other engineering requirement. However, in the large-scale area with hilly or mountainous terrain will be difficult to perform the traditional inspection by tracking.

Unmanned Aerial Vehicle by using drones is one of the solutions to ease site survey and inspection, especially in difficult terrain area. UAV can be mobilized quickly, require minimal human resources and facilitate rapid on-site assessment and hazard identification. Inaccessible and hazardous terrain can be inspected in real-time allowing assessment methodology to be adapted on site.

Over the past 5 years, the popularity of multi-rotor UAV or quadcopters systems has increased due to their widespread commercial availability, relatively low cost, sensor technology, easy to operation, remote control, and performance (CASA, 2015, Walker, 2016).

Aerial survey (photogrammetry) can be combined by the topographic survey to determine accurate field contour where the limitation of UAV is difficult to obtain actual contour in the area covered by lush vegetation and shadows cast by the sun. 
This paper gives the understanding of UAV application to detect the landslide and hazard around Cipularang Toll Road KM. 92 in Indonesia. It helps more understanding to around site condition and to ease geotechnical engineer in deciding the coverage area of slope protection against the future landslide (Fig. 2.).

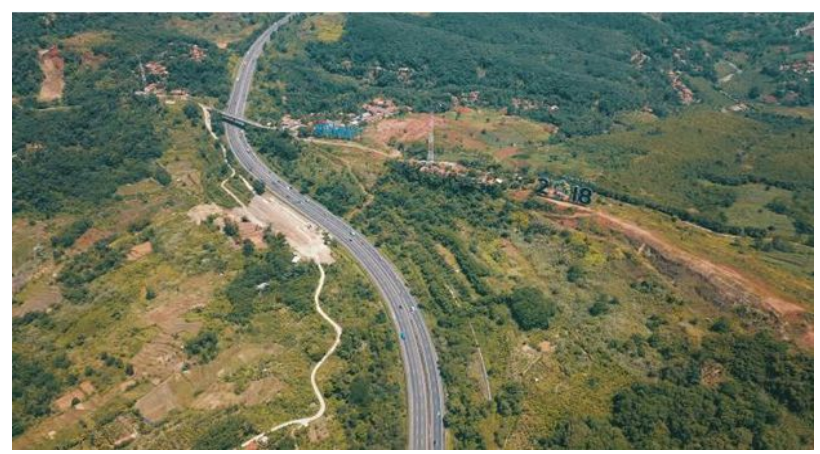

Fig. 2. Cipularang Toll Road KM. 92, Indonesia (Doc. by UAV)

\section{The material And method}

In term of landslide investigation, both of aerial survey and ground survey need to be performed. The Ground survey includes site investigation by using deep boring, $\mathrm{CPT}$, and monitoring slope movement using inclinometers.

\subsection{UAV}

Recent studies and papers have reported on the use of UAV for photogrammetric surveys of landslide and risk assessment. UAV has been used for remote sensing and object-oriented mapping of slow-moving landslides. In advance, Photogrammetry provides overlapping vertical stereo pair photographs that allow ground contours to be mapped by special equipment. The photographs can be used by geotechnical engineers and geologists to examine the landslide. It shows the vertical height differences, appear exaggerated, showing the scarps and slope features with excellent relief.

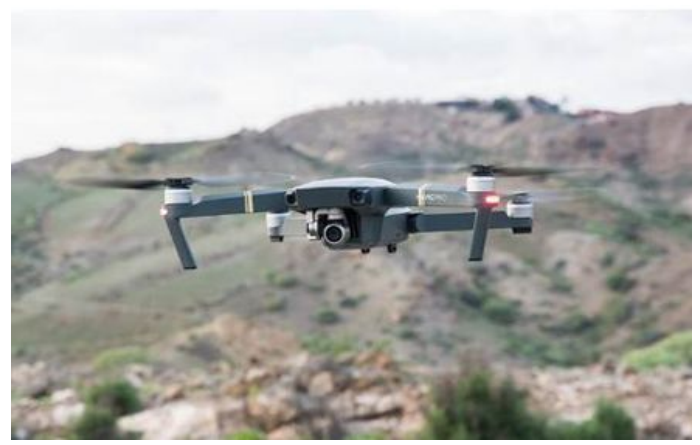

Fig. 3. Unmanned aerial vehicle [4]

The aircraft flies at a speed of about $16 \mathrm{mph}$ and takes photographs using $4 \mathrm{~K}$ camera lens which commonly used for landslide mapping with fully remote controlled and connected to the smartphone as a screen (fig. 3.) The degree of detail in the photographs depends on the height of the drone above the ground. Altitude can be decreased in order to get more detail of the photographs.

Bright sunshine provides the best contrast for mapping. However, if the site covered with many trees, shadows cast by the sun make ground mapping difficult; for this situation, a light overcast day provides better mapping conditions. It is highly recommended to check weather overcast before the flight. Therefore, in a landslide covered by dense vegetation, ground traverses may be needed to supplement aerial photography. In general, however, a contoured site plan obtained from aerial photographs is the best method of surveying a medium to large size landslide.

Basically, UAV uses Global Positioning System (GPS) and Inertial Measuring Unit (IMU) techniques. A GPS receiver is connected to the camera and is triggered at the same time as each photograph, giving the precise coordinates of the plane's position at the center of the photograph. However, some ground control is still necessary. A more recent development is to include an Inertial Measuring Unit (IMU), a form of gyroscope that can measure the angle of the camera during flight. Although still not perfect, it offers the possibility of eliminating the need for ground control.

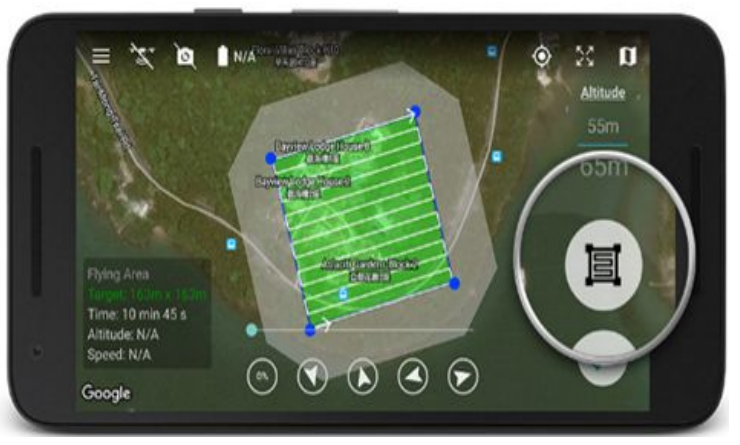

Fig. 4. Loaded map and flight orbit on a smartphone

The result of an aerial survey is usually provided to engineer as a contour map. The contour map and also the $3 \mathrm{D}$ model of the slope or cliff can be generated by using computer software based on aerial photographs in advance. Before take-off, the survey area must be loaded on the map and determine the flight orbit (fig. 4.).

\subsection{Site investigation and observation}

By using UAV, engineers can determine the general area and predict the mechanism of landslide precisely. They can determine the affected areas and wider footage of landslide area. UAV can provide photographs that can not be taken on the ground. However, additional site investigation and observation still necessary. 

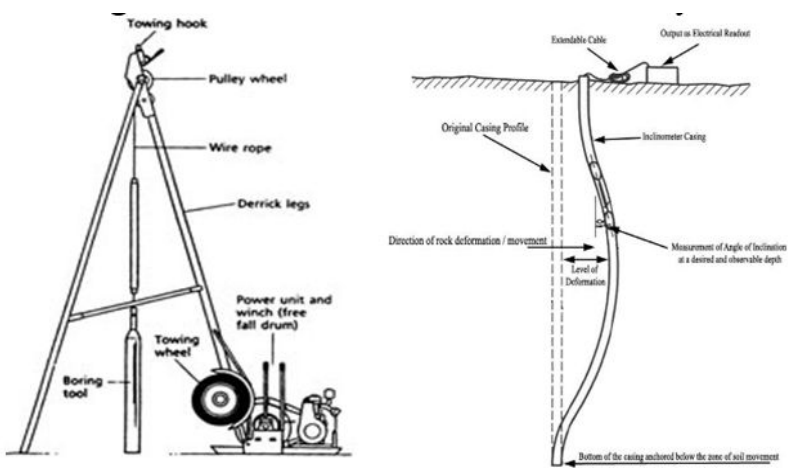

Fig. 5. Soil boring tools and inclinometer instrument

Site investigation by using deep boring can determine the soil stratification along depth which is used to obtain soil material or debris layer which potentially slides(Fig. 5.). Monitoring inclinometer can be performed by placing the inclinometer pipe after deep boring and grouted in a time than monitoring is conducted periodically depends on the rainfall intensity, visual crack or surface movement, and design requirement. Meanwhile, site observation can give more detail information due to the specific area which has already shown with an aerial photograph in general.

\section{Case study}

Landslide already detected in November 2008 at Cipularang KM. 92 Toll Road caused existing retaining wall collapse [7]. Cipularang KM. 92 Toll Road had been constructed since 2005 on fill material and many ground movements had been reported until present.

Based on the geological map proposed by Sudjatmiko, 2003, Cipularang KM. 92 Toll Road was on Qos formation which dominated by sandstone, Breccia tuff, and agglomerate(Fig. 6.).

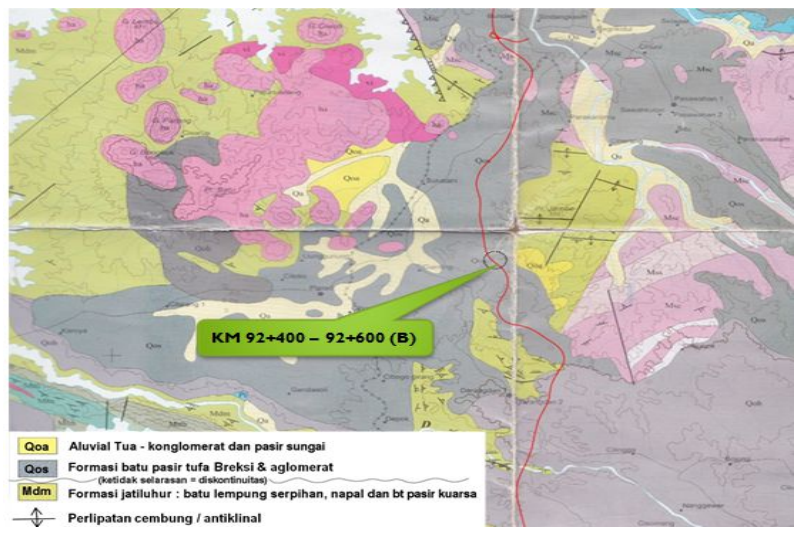

Fig. 6. Geological maps of Cipularang KM. 92 Toll Road

\subsection{Landslide report in 2008}

The main scarp was identified along $300 \mathrm{~m}$ parallel with the Toll Road (Fig. 7.). Site observation showed the Toll Road was in landslide body on debris material. Based on surface condition, the debris material dominated by colluvium which deposits at that area many years ago.

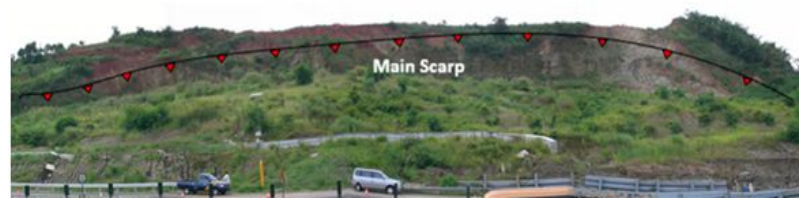

Fig. 7. Main scarp detected at the slope nearby Toll Road

Debris material was dominated by silty clay and clay shale was found in a certain area which was a degradable material due to exposure and contact with water (Fig. 8.).
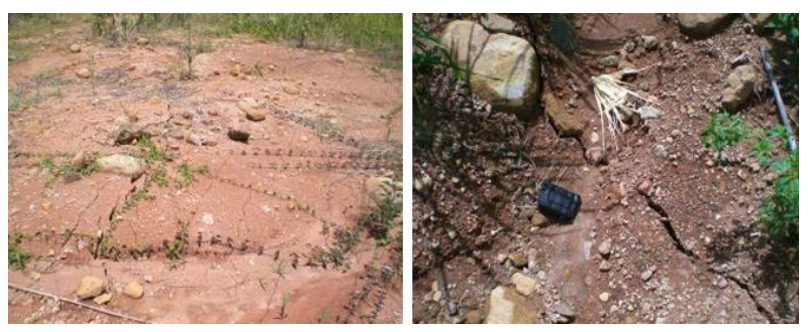

Fig. 8. Debris material on main body

The main body of landslide also fully saturated. Many springs were identified, besides the particular area was used by the local community as a paddy field (Fig. 9.). It triggered the slope movement because the water cannot be drained out of the slope.
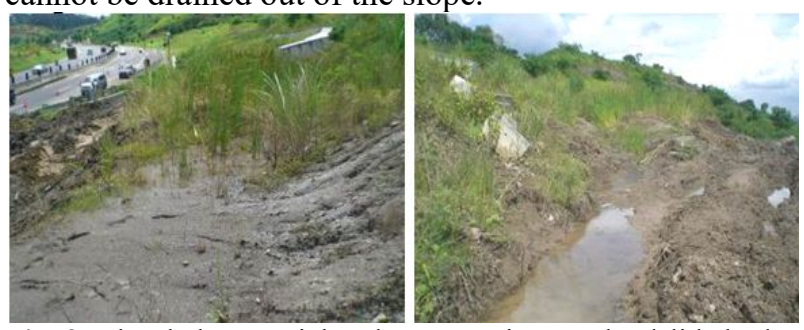

Fig. 9. Clayshale material and water springs on landslide body

A landslide caused the retaining wall collapse. The mechanism of the landslide was expected as a progressive landslide. The main landslide triggered another landslide until it reaches the retaining wall (combination soldier pile and steel plate). Determination of landslide mechanism is based on site observation only where the main scarp was identified, the other important thing to be found was accumulation zone at the toe of the slope. It usually represented by heaving on the slope toe (Fig. 10.). Heaving area was identified besides the Toll Road clearly (Fig. 11.).

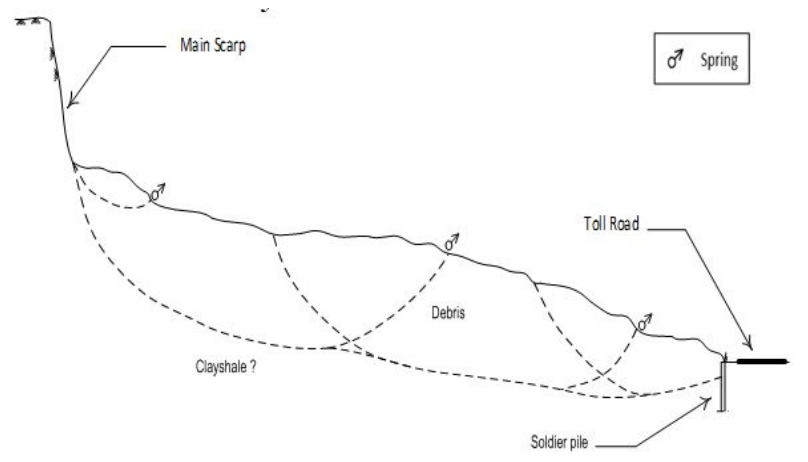


Fig. 10. Mechanism of landslide

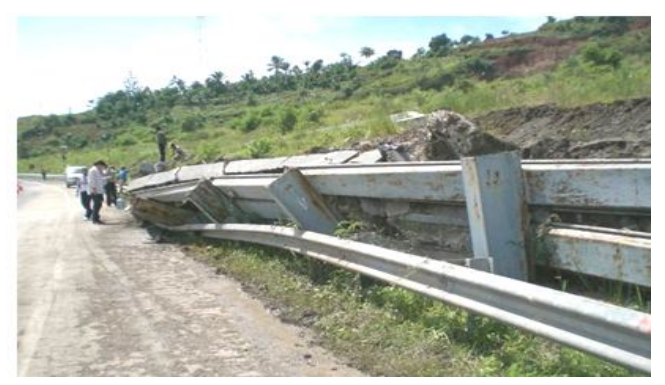

Fig. 11. Heaving area stopped at retaining wall

\subsection{Landslide report in 2009}

In July 2009, a landslide occurred at the other Toll Road side of the previous landslide (Fig. 12). Similar with 2008 landslide, the area already protected by soldier pile. However, the soldier pile was not covered all of the movement areas[8].

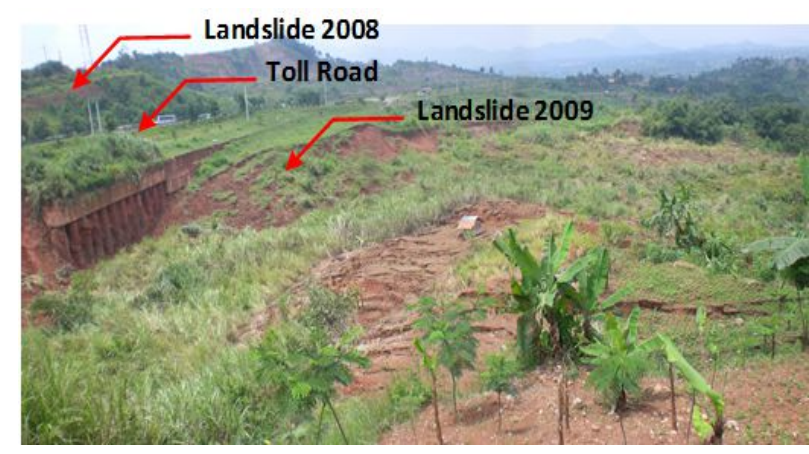

Fig. 12. The position of landslide 2009

The material of landslide similar with the main scarps in 2008 which was consist of silty clay material as topsoil. Surrounding area was indicated as vacant land and particularly used for farming by the local community. There was an inclinometer nearby landslide area. The monitoring result showed the sliding plane was in $21 \mathrm{~m}$ below ground level.

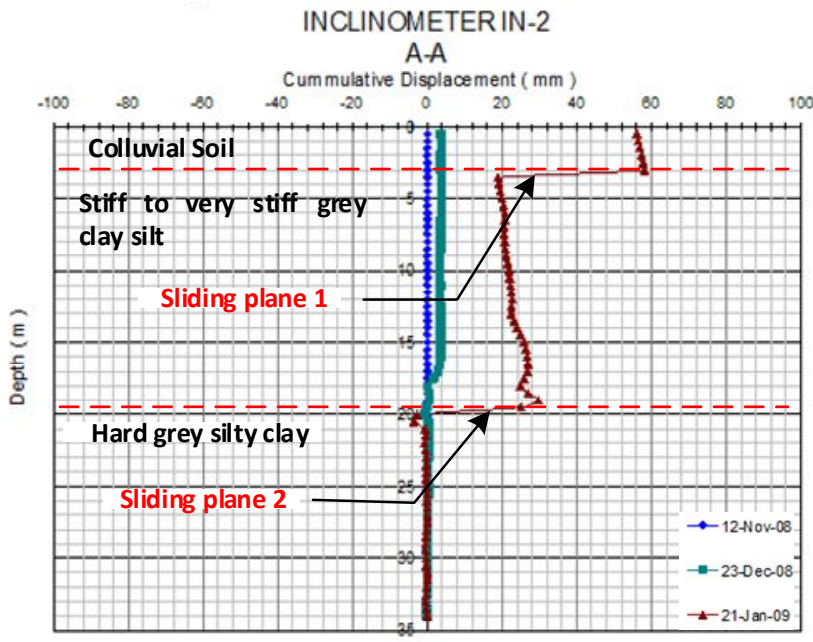

Based on the inclinometer result (Fig. 13.), the mechanism of the landslide was the same which known as the progressive landslide. It showed two sliding planes at $4 \mathrm{~m}$ depth and $20 \mathrm{~m}$ depth. Sliding plane 1 is known as the colluvial layer and the deeper sliding plane is expected as clay shale layer.

To verify the mechanism of the landslide on both sides of Cipularang KM. 92 Toll Road, it needs to perform aerial photograph to get better footage of overall coverage landslide area.

\subsection{Aerial photogrammetry using UAV}

UAV was performed at Cipularang KM 92. Toll Road to obtain the overall understanding of both landslide phenomenon. By using an aerial photograph, it can help the engineers to decide long-term slope protection for all coverage area (Fig. 14). The main objective to be found in the coverage landslide area because it is worried the two previous incidents only the small part of the massive landslide.

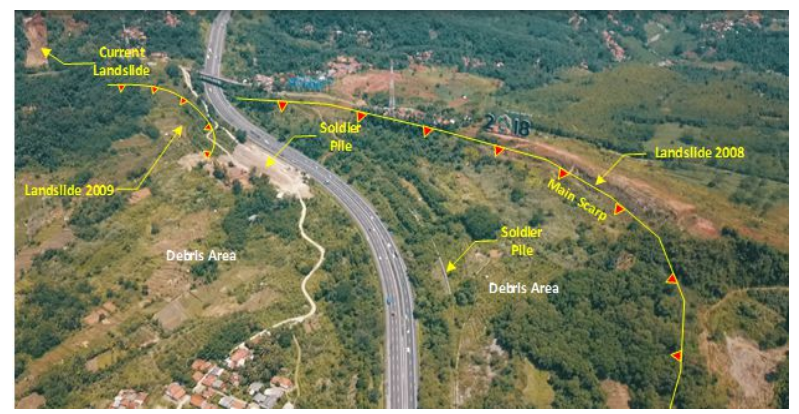

Fig. 14. Aerial photograph of Cipularang KM. 92 Toll Road

Based on topography contour, the main scarp can identify in the following figure (Fig. 15.). Soldier pile only design in a particular area using 1 layer bored pile. With a huge mass of landslide body, soldier pile must be reinforced by additional slope protection. Besides, the coverage area of the soldier pile is not enough to cover the whole movement area. Soldier pile still in the landslide body area.

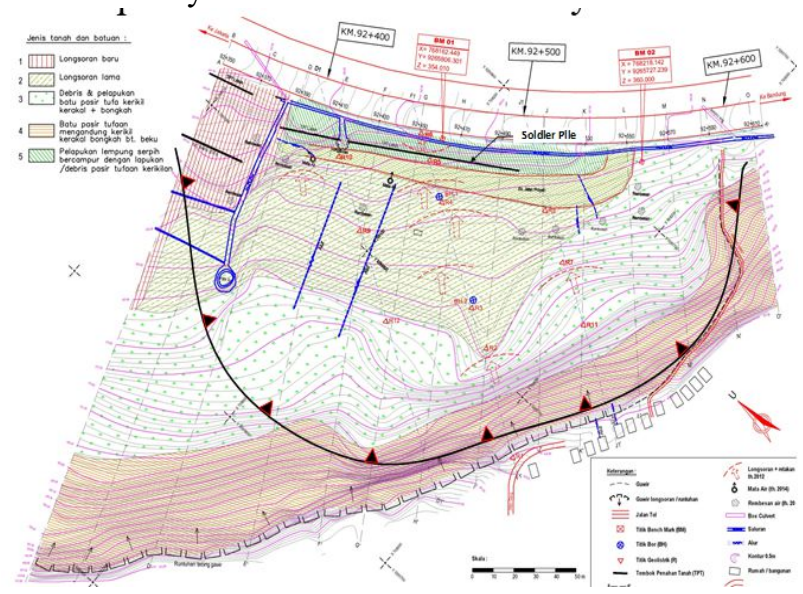

Fig. 15. Contour Cipularang KM. 92 Toll Road

Fig. 13. Inclinometer result at landslide 2009 


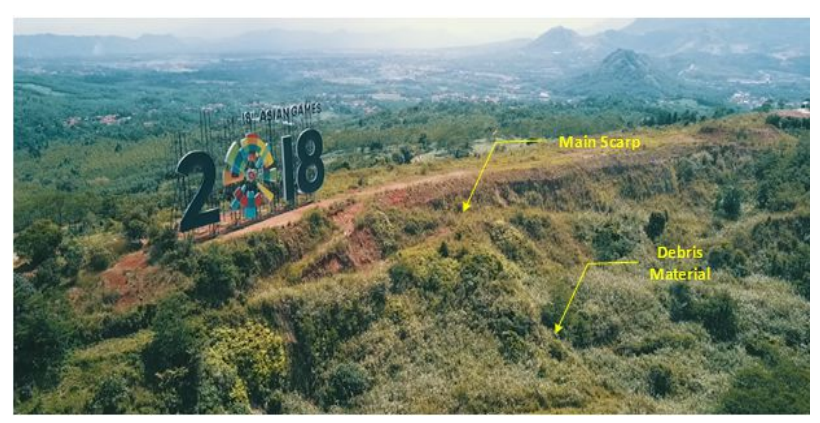

Fig. 16. Main scarp condition [Doc. March 2018]

Aerial photographs showed the main scarps was wider than the slope protection coverage (Fig. 16 and Fig. 17.). So that the slope movement can still occur especially for the area which was not covered by soldier pile or any other retaining wall. Nowadays, debris material was covered by vegetation and the certain area still saturated by water ponding.

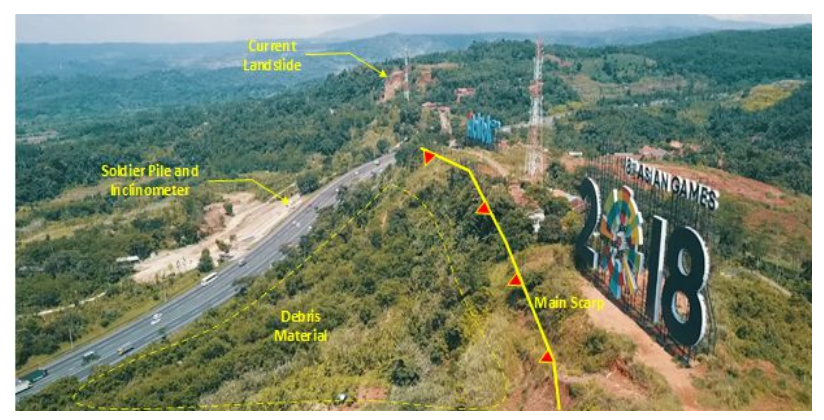

Fig. 17. Main scarp condition Towards Toll Road [Doc. March 2018]

\subsection{Result and discussion}

In October 2015, additional slope reinforcement was performed by using two layers of bored piles behind the existing soldier pile (Fig. 18). For the opposite slope area, it used ground anchor beside the slope of Toll Road embankment to increase slope stability.

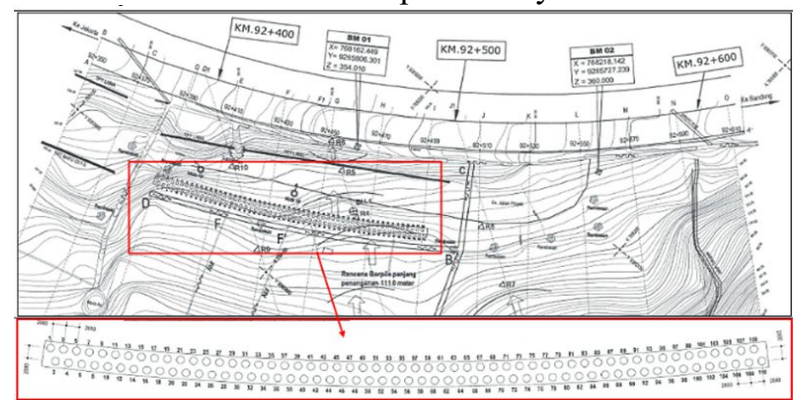

Fig. 18. Lay out of additional slope reinforcement using double layers of bored piles

According to aerial photographs, site condition still contains saturated debris material. Debris material was an unstable material and tend to be an additional load for the slope. Since the forces tending to cause movements downslope are essentially gravitational, a simple approach to increasing stability is to reduce the mass of soil involved in the slope, benched slopes, reduced excavation depths, surface and subsurface drainage, and lightweight fill. All of these possibilities reduce driving forces and all have been successfully used at one time or another.

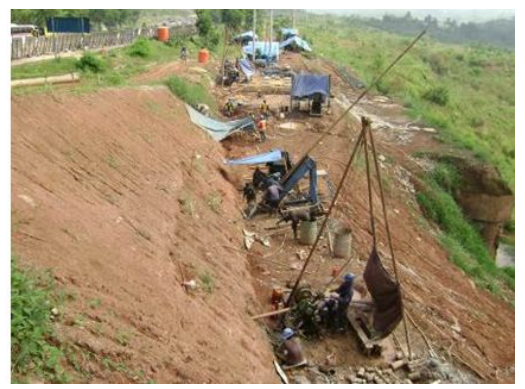

Fig. 19. Additional ground anchor to stabilize toll road embankment behinds soldier pile

Because of its high stabilization efficiency in relation to design and construction costs, drainage of surface water and groundwater is the most widely used and generally the most successful slope stabilization method (Committee on Ground Failure Hazards, 1985). Of all possible schemes to be considered for the correction of existing or potential landslides, proper drainage is probably the single most important. Proper surface drainage and subsurface drainage (i.e. sub-drain and horizontal drain) can be implemented on the slope along coverage area which was shown in the aerial photographs (Fig. 20.).

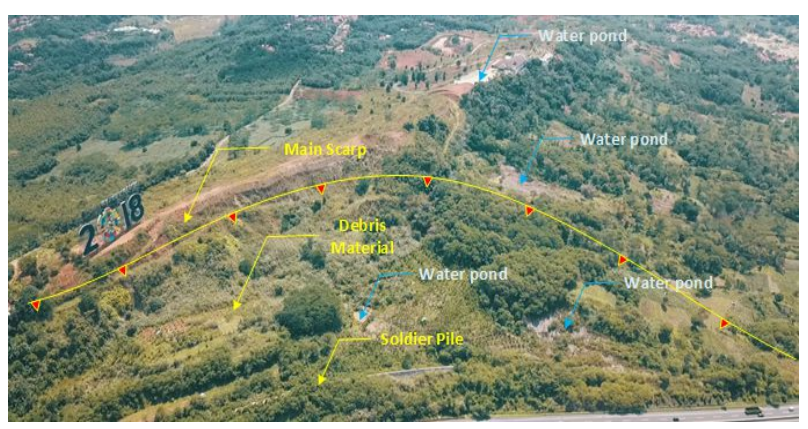

Fig. 20. Recent condition oflandslide body [Main Scarp]

\section{Conclusions}

One of the greatest benefits of UAV assessments is a significant reduction in field time due to the ability to rapidly survey large areas, especially in Cipularang KM. 92 Toll Road was in operation period which was not able to cross the Toll Road. By using UAV, engineers will get a better point of view related with landslide mechanism of the overall area rather than traditional inspection which will cost longer time and limited viewpoints.

It is recommended to combine site investigation, observation, and photogrammetry using UAV. UAV will give general footage of potential hazard area and obtain specific condition, site investigation by using deep boring, monitoring, etc can support better understanding for engineer or geologist to decide and make their technical judgement. If the mechanism of landslide and hazard have already known accurately, the decision of 
slope protection and preventive action (i.e. monitoring) will be reliable.

Authors would like to thank Universitas Katolik Parahyangan for supporting and motivation to contribute to this international event.

\section{References}

1. CASA.Remote Piloted Aircraft Systems, Civil Aviation Safety Authority, accessed 6 June 2016. http://www.casa.gov.au/aircraft/landingpage/remotely-piloted-aircraft-system. (2015)

2. Cruden, D.M. A Simple Definition of a Landslide. Bulleting od the International Association of Engineering Geology, No. 43, pp. 27-29 (1991)

3. D. H. Cornforth. Landslide in Practice: Investigation, Analysis, and Remedial/Preventive Options in Soils, pp. 478-485 (2005)

4. I.C. Jaukovic, et.al. Unmanned Aerial Vehicles: A New Tool For Landslide Risk Assessment. Proceedings of the $11^{\text {th }}$ ANZ Young Geotechnical Professionals Conference - 11YGPC Queenstown, New Zealand. (2016)

5. J. M. Duncan and S. G. Wright. 2005. Soil Strength and Slope Stability. pp 247-249.
6. Marijan Car, et.al. 2016. Application of Unmanned Aerial Vehicle for Landslide Mapping. SIG 2016, International Symposium on Engineering Geodesy, Varazdin, Croatia.

7. PT. Geotechnical Engineering Consultant, 2008. Special Reports on KM Avalanches. $92+400$. Cipularang Toll Road. Bandung.

8. PT. Geotechnical Engineering Consultant, 2009. Special Reports on KM Avalanches. $92+800$ Cipularang Toll Road. Bandung.

9. P. V. Gorsevki, et.al. Landslide Detection and Susceptibility Mapping Using LiDAR and an Artificial Neural Network Approach: a Case Study in the Cuyahoga Valley National Park, Ohio. Journal of the International Consortium on Landslides: Springer, vol. 13, number 3, pp. 467468, (June 2016).

10. Robert E. Spicher, et.al, Transportation Research Board. Landslides: Investigation and Mitigation, pp. 442-452 (1996)

11. Varnes, D.J. Slope Movement Types and Processes. Chapter 2, Landslides: Analysis and Control, Special Report 176, Transportation Research Board, National Academy of Sciences, Washington, D.C., 234 pp.(1978)

12. Walker, B. Developing High Sensitivity Magnetometers for Unmanned Aircraft. FastTIMES, pp. 16-22 (2016) 